\title{
FORMAÇÃO INICIAL DE PROFESSORES E O PROCESSO ARGUMENTATIVO
}

\author{
Marília Berberick*
}

Resumo: O presente trabalho apresenta a pesquisa de mestrado desenvolvida no interior do Programa de Pós-Graduação em Educação da Universidade Federal de Juiz de Fora - PPGE/UFJF, que teve como foco o estudo sobre o papel da argumentação na formação inicial de professores do curso de Pedagogia da Universidade Federal de Juiz de Fora. Tal pesquisa está embasada pelas contribuições de autores da teoria sócio-histórico-cultural: Bakhtin (1995) e Vygotsky (2007) e fundamentada sob o viés da Pesquisa Crítica de Colaboração - PCCol (MAGALHÃES, 2004). A discussão dos dados da pesquisa está pautada nas categorias argumentativas, com base em Perelman e Olbrechts-Tyteca $(2005)$, Liberali $(2008,2009)$ e Schapper (2010), com o levantamento dos tipos de argumentos, operadores argumentativos e dêiticos.

Palavras-chave: Formação Inicial de Professores. Educação Infantil. Pesquisa Crítica de Colaboração.

Para início de diálogo...

Enquanto eu tiver perguntas e não houver resposta continuarei a escrever.

Manoel de Barros

O presente artigo é fruto da pesquisa de mestrado "Educação Infantil e a Formação Inicial de Professores: com a palavra, a argumentação", desenvolvida no interior da Linha de Pesquisa Linguagem, Conhecimento e Formação de Professores do Programa de PósGraduação em Educação da Universidade Federal de Juiz de Fora - PPGE/UFJF, que objetivou compreender o papel da argumentação na formação inicial de professores do curso de Pedagogia da Universidade Federal de Juiz de Fora.

A pesquisa foi realizada a partir de observações das aulas da disciplina de Fundamentos Teórico-Metodológicos em Educação Infantil I, durante o segundo semestre de 2014, em uma turma do 2 ํ período do curso de Pedagogia da Universidade Federal de Juiz de Fora, por uma sessão reflexiva com os alunos e uma entrevista dialógica com a professora da disciplina.

\footnotetext{
* Mestra em Educação pela Universidade Federal de Juiz de Fora, Supervisora Pedagógica na Prefeitura de Rio Pomba, email: mariliaberberick@yahoo.com.br.
} 
O objetivo foi investigar como ocorre a argumentação, na disciplina de Fundamentos Teórico-Metodológicos em Educação Infantil I, entre aluno-professor-aluno, e se tal movimento possibilita uma formação crítica do futuro professor que atuará com as crianças de 0 a 3 anos.

Por meio da análise dos dados de pesquisa, pautadas nas categorias argumentativas, com base em Perelman e Olbrechts-Tyteca (2005), Liberali $(2008,2009)$ e Schapper (2010), com o levantamento dos tipos de argumentos, operadores argumentativos e dêiticos, foi possível tecer discussões e considerações a respeito dos resultados do campo de investigação.

\section{O Levantamento da Literatura: a relevância da pesquisa}

A relevância de se pensar a respeito da formação de professores, seja inicial ou continuada, vem sendo abordada por muitos pesquisadores que, em seus estudos, revelam diferentes inquietações. Procurando trazer uma nova discussão sobre a formação inicial de professores, mais especificamente, no que diz respeito ao potencial da argumentação para a formação crítico-reflexiva do futuro professor, a pesquisa apresenta o levantamento da literatura de trabalhos publicados no período de 2004 a 2013, que tecem relações com a proposta de investigação deste trabalho.

O levantamento da literatura foi realizado nos sites da Associação Nacional de PósGraduação e Pesquisa em Educação - ANPEd ${ }^{1}$, nos Anais do Seminário de Grupos de Pesquisas sobre Crianças e Infâncias - GRUPECI, no portal de periódicos da Coordenação de Aperfeiçoamento de Pessoal de Nível Superior - CAPES ${ }^{2}$, no site da Scientific Electronic Library Online - Scielo ${ }^{3}$ e também no site da Biblioteca Digital Brasileira de Teses e Dissertações BDTD $^{4}$.

É importante destacar que o levantamento da literatura não abrange o banco de teses e dissertações da CAPES, pois, no período das buscas, estavam disponíveis somente os trabalhos defendidos nos anos de 2011 e 2012. Isso porque o banco estava passando por atualizações dos dados para garantir a fidedignidade dos mesmos.

No site da ANPEd, a pesquisa compreendeu da 27ạ Reunião Anual à 36a Reunião, agora caracterizada como Reunião Nacional da ANPEd. Na busca realizada nos anais do GRUPECl, o levantamento reuniu três dos cinco seminários já realizados, tendo em vista que os dois últimos ocorreram nos anos de 2014 e 2016, período não abrangido no levantamento da literatura nesta pesquisa. Para seleção dos trabalhos, foi realizada a leitura dos títulos e/ou resumos dos artigos apresentados e, a partir desse primeiro movimento, foram selecionados 
aqueles que teciam uma relação com a Formação de Professores, a Argumentação e a Pesquisa Crítica de Colaboração.

No site da ANPEd, a pesquisa deu-se em dois Grupos de Trabalhos - GTs: GT7 Educação de Crianças de 0 a 6 anos e GT8 - Formação de Professores, que estão estritamente ligados à presente investigação

Já nos sites da CAPES, do Scielo e da BDTD, a investigação deu-se por meio das palavras-chave: formação de professores e argumentação, formação de professores $e$ educação infantil e formação de professores e pesquisa crítica de colaboração.

A partir dos dados é possível dissertar que os trabalhos investigados nos dois GTs da ANPEd, em 7 trabalhos selecionados no GT7 - Educação de Crianças de 0 a 6 anos, foi observado que a formação do professor de educação infantil ainda apresenta grandes questões para o debate da formação de tal profissional. Isso porque, por muitos anos, a formação do professor para atuação na infância não ocupava um espaço efetivo nas pautas do cenário educacional brasileiro. Porém, na década de 1990, pós Constituição de 1988 e Lei de Diretrizes e Bases da Educação Nacional de 1996 - LDB 9394/96, tal formação passou a ser reconhecida. Os artigos trouxeram também a preocupação dos pesquisadores com a docência na educação infantil e a necessidade de os cursos de Pedagogia repensarem seus currículos para contemplarem tal formação.

Com relação aos seis trabalhos selecionados no GT8 - Formação de Professores, foi possível observar que, assim como os artigos do GT7, também, em sua maioria, trazem a preocupação com a formação e ação docente de professores para a atuação na educação infantil. Porém, ainda majoritariamente, a preocupação dos pesquisadores está mais especificamente voltada para a formação inicial e/ou para a inserção de tais profissionais no trabalho docente.

Dos 14 trabalhos selecionados dos três Seminários de Grupos de Pesquisas sobre Crianças e Infâncias - GRUPECI, procurei trazer a discussão, dividindo tais publicações em três eixos: (1) A formação de professores para atuação na educação infantil; (2) A Pesquisa Crítica de Colaboração - PCCol, como uma possibilidade de se pensar a formação continuada de professores para a primeira infância e (3) Diálogos entre a formação inicial e o estágio supervisionado em educação infantil.

Os trabalhos selecionados a partir dos sites de pesquisa Scielo e portal de periódicos da CAPES, do total de 482 trabalhos selecionados nos dois referidos sites, a partir das palavraschave formação de professores e argumentação, formação de professores e educação infantil, formação de professores e pesquisa crítica de colaboração, somente 8 artigos relacionam-se à temática da presente investigação. 
Já dos 300 artigos levantados a partir das palavras-chave "formação de professores e educação infantil", somente 6 trabalhos tecem relações com minha proposta de pesquisa.

Por fim, 10 trabalhos de teses e dissertações, selecionados no site de pesquisa Biblioteca Digital Brasileira de Teses e Dissertações - BDTD, a partir das palavras-chave formação de professores e argumentação, formação de professores e educação infantil, formação de professores e pesquisa crítica de colaboração, dialogam com este trabalho.

É importante destacar que, após o levantamento dos trabalhos nos sites da ANPEd, CAPES, Scielo, BDTD e nos trabalhos do GRUPECI, as pesquisas foram realizadas com o intuito de saber o já discutido e produzido sobre a formação de professores, atrelado à argumentação, à educação infantil e à pesquisa crítica de colaboração, e deste modo foi possível trazer estudos que tecem alguma relação com a temática deste trabalho.

A seguir, um diagrama elaborado a partir do levantamento da literatura e que ilustra o cômputo de trabalhos que dialogam com a proposta de pesquisa da dissertação.

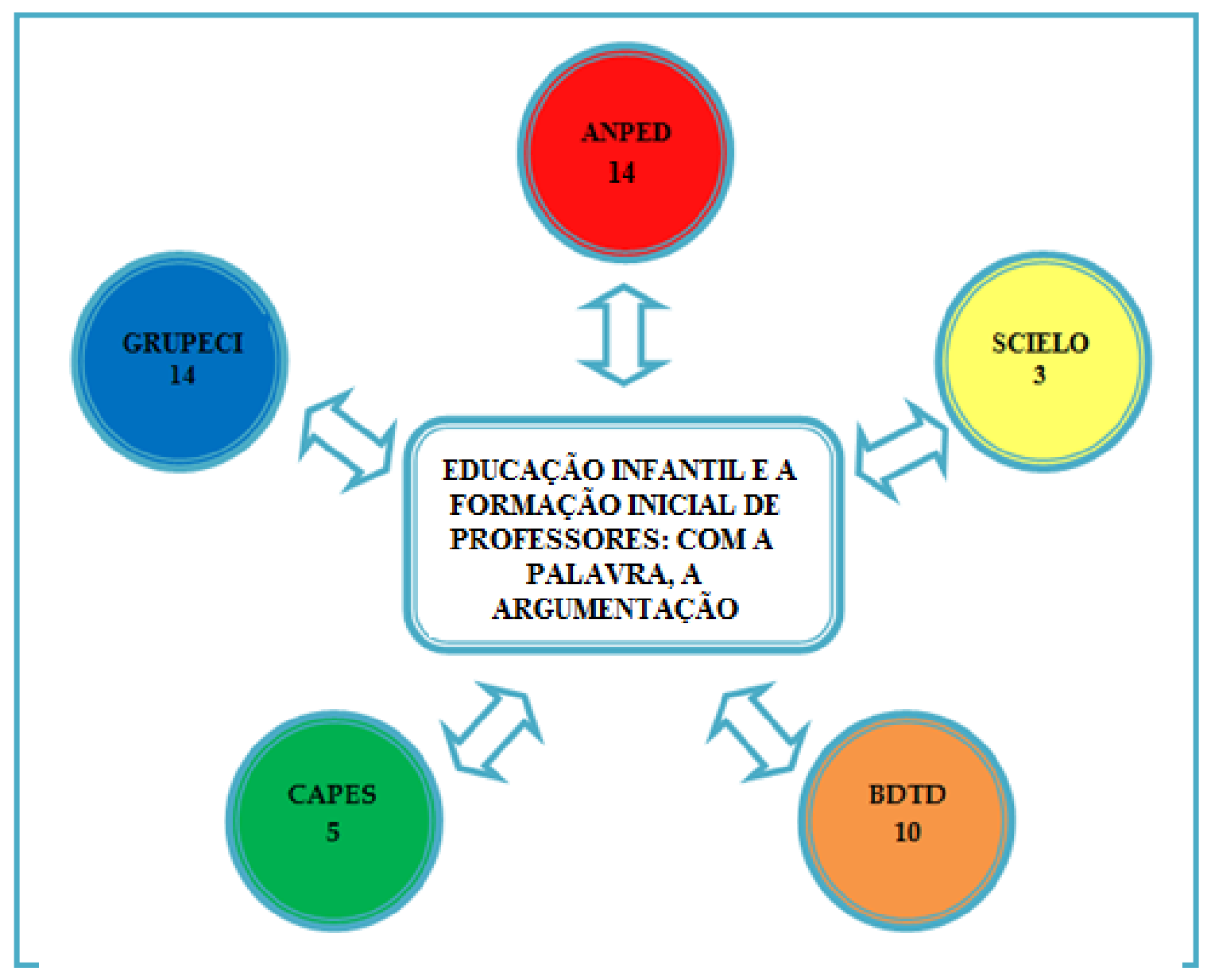

Figura 01 - Diagrama do levantamento da literatura 2004 a 2013 
O levantamento da literatura evidenciou a grande relevância de se pensar e refletir sobre a formação de professores para a Educação Infantil e sobre a necessidade de tal formação estar constantemente em pauta nas políticas públicas educacionais e nos grandes encontros de docentes do país e também a importância de mudanças curriculares no curso de Pedagogia, pois a contribuição de tal curso para a formação de professores da Educação Infantil ainda é parcial.

Outro ponto que pode ser destacado é a necessidade de que sejam pensadas propostas de formação de professores de Educação Infantil que visem à transformação da prática no trabalho com as crianças pequenas. $O$ intuito foi o de refletir sobre a citada temática, para construir um saber novo, ou seja, uma nova prática.

Algumas pesquisas destacaram a relevância do papel da argumentação na formação de professores e, assim como este trabalho, essas se embasam também na perspectiva crítica de colaboração para se pensar tal formação.

Cumpre notar também algumas investigações selecionadas, que destacaram a importância do estágio supervisionado em Educação Infantil para a formação do docente para atuação em tal segmento. Isso porque, segundo os pesquisadores, o estágio se constitui como um primeiro momento de vivenciar e poder relacionar a teoria com a prática.

É possível observar que a formação docente para atuação na Educação Infantil ainda precisa ser pensada e refletida, criticamente, pelos formadores de professores, pelos futuros docentes, pelos professores atuantes em tal segmento, bem como por todos os responsáveis e envolvidos na educação das crianças pequenas.

Desse modo, destaco que tal carência caracteriza-se como o ponto mais relevante da presente pesquisa, pois esta pretende apresentar, a partir de um determinado contexto, a importância e as contribuições do trabalho de um formador de professores, por meio do processo argumentativo, na formação inicial do pedagogo, para que tal formação seja crítica e reflexiva para esse profissional.

\section{A perspectiva sócio-histórico-cultural: reflexões teóricas}

A pesquisa, fundamentada na teoria sócio-histórico-cultural com foco na argumentação, foi embasada pelas contribuições de autores da teoria sócio-histórico-cultural: Mikhail Bakhtin (1995) e Lev Vygotsky (2007).

Por meio das perspectivas dos autores supracitados, é necessário destacar que a linguagem, sob a égide do princípio dialógico, configura-se como um elemento que permite, 
por meio dos enunciados, o desenvolvimento mental do sujeito e, consequentemente, o planejamento do pensamento. Para Vygotsky (1993), o sujeito se constitui por meio da linguagem, vez que ela exerce importante papel de intercâmbio social, em que os sujeitos criam e recriam sistemas de linguagem. É também pela linguagem que é possível ordenar o real, conferindo, assim, a ela a função de instrumento do pensamento. Porém, Bakhtin aponta que a linguagem não revela somente a expressão do pensamento, da fala e da comunicação com o outro, mas o encontro e o confronto de subjetividades, ou seja, o embate de diferentes perspectivas sociais.

Para Amorim (2004, p.97), "não há linguagem sem que haja um outro a quem eu falo e que é ele próprio falante/respondente; também não há linguagem sem a possibilidade de falar do que um outro disse". É, portanto, no fluxo dialógico da linguagem, que existe a possibilidade da troca de papéis dos envolvidos na cena enunciativa, pois ora o sujeito se posiciona como locutor, ora como ouvinte. Compreendendo, assim, o movimento das palavras e contrapalavras no fluxo da interação verbal, encontra-se o que o Bakhtin definiu como enunciação. Esta se caracteriza como fruto da interação de dois sujeitos em um determinado contexto social. Bakhtin (2011, p. 272) afirma que todo enunciado é um diálogo, desde a comunicação entre duas pessoas ou até mesmo as interações entre os enunciados. Nas palavras do autor, "cada enunciado é um elo na corrente complexamente organizada de outros enunciados".

Complementando tal pensamento, Jobim e Souza (1994) explicita que, para Bakhtin, as interações dialógicas caracterizam-se, também, como relações de sentidos criadas pelos sujeitos ao longo dos tempos e espaços, porque o sentido da palavra variará de acordo com o contexto no qual ela circula. É, então, no movimento da interação verbal que a linguagem destaca-se na cena enunciativa. Isso porque é por meio do conflito de ideias, dos diferentes sentidos que emergem no/do diálogo entre locutor e interlocutor que as palavras tomam uma nova significação e a linguagem constitui-se como elemento essencial para a organização da ação humana.

Com base nesses pressupostos, é possível inferir que o trabalho buscou no percurso da pesquisa, por meio de um movimento dialógico-dialético, de ouvinte-locutor, o entrelaçamento das palavras e contrapalavras e, desse modo, possibilitar que os enunciados compartilhados entre os participantes possam ganhar, no interior desta investigação, novas composições coletivas.

Para discussão dos dados da investigação discorro abaixo acerca de conceitos imprescindíveis para a compreensão de toda a pesquisa, bases da análise e da interpretação dos dados. 
Primeiramente, trago os conceitos de sentido e significado, zona de desenvolvimento proximal, mediação e colaboração crítica, escrita essa construída não por meio de tópicos, já que a abordagem a qual o estudo está fundamentado acredita em tais conceitos vistos como constituintes de categorias indissociáveis, quando se discute formação de professores pautada em uma perspectiva crítico-reflexiva.

A discussão de sentido e significado é imprescindível, pois numa perspectiva de investigação crítico-colaborativa, fundamentada na abordagem sócio-histórico-cultural, tais conceitos possibilitam compreender como ocorre o compartilhamento de sentidos por uma determinada comunidade semiótica ${ }^{5}$, no caso desta investigação, a disciplina de Fundamentos Teórico-Metodológicos em Educação Infantil I, no intuito de compreender a construção de novos significados mais ou menos estáveis para tal comunidade.

Para os autores, significado é apresentado como algo que foi compartilhado entre os sujeitos, ou seja, define-se coletivamente, por meio do social. Logo, pode-se afirmar que tal conceito decorre do compartilhamento dos sentidos destacados pelos indivíduos, ganhando, no interior das enunciações, status de significação. Nas palavras de Vygotsky (1993, p.125), “o significado é apenas uma das zonas do sentido, a mais estável e precisa".

Ao encontro de Vygotsky, infere-se, grosso modo, que Bakhtin expressa que o significado da palavra é construído por meio das relações entre os sujeitos que compartilham um mesmo campo de discussão, ou seja, são os elementos que compõem a enunciação e que são reiteráveis e idênticos cada vez que são repetidos. O sentido, por sua vez, é subjetivo, porque, na relação entre os pares, cada sujeito carrega consigo suas experiências e vivências e procura compartilhar com outros, em uma situação dialógica e colaborativa, para que juntos possam partilhar de um significado mais ou menos estável para o grupo.

É interessante notar que é por meio dos movimentos de significação que os sentidos são compartilhados, desestabilizando, assim, a significação. Segundo Schapper (2010, p. 3637), "essa desestabilização, posta nos múltiplos movimentos do significado, que constituem os diversos sentidos, possibilita a uma determinada comunidade semiótica alcançar novamente um significado mais ou menos estável". Isso acontece porque é por meio da interação entre os sujeitos que cada participante, no fluxo dialógico, pode expor os sentidos compartilhados com outras comunidades semióticas e, a partir desse movimento, por meio do embate de ideias, construir um significado mais estável para a comunidade que se encontra em diálogo.

É, então, no movimento da palavra e contrapalavra que os significados são desestabilizados para, posteriormente, estabilizarem-se no interior de uma determinada comunidade semiótica. 
Outros dois conceitos que ganham destaque na teoria sócio-histórico-cultural, e no trabalho, são os de Mediação e Zona de Desenvolvimento Proximal - ZDP. A última foi definida por Vygotsky (2007) como a distância entre o nível de desenvolvimento real, considerado por esse autor como a ação que o sujeito realiza de maneira independente, e o nível de desenvolvimento potencial, aquilo que o sujeito ainda não realiza independentemente, ao contrário, alcança com o auxílio de um sujeito mais experiente.

Segundo Newman e Holzman (2002), Vygotsky atribuiu à ZDP papel de destaque, pois, para o estudioso, o desenvolvimento do sujeito não é caracterizado somente pelo que já está amadurecido, mas, sobretudo, pelo que se encontra entre o que está maduro e o que ainda não foi amadurecido, ou seja, o intervalo que se encontra em amadurecimento, definido por Vygotsky como ZDP.

Para o autor russo, o desenvolvimento ocorre de forma espiral e não em círculos, pois, a cada aprendizado, o sujeito alcança um nível superior, em que o desenvolvimento passa por um mesmo ponto todas as vezes. Por meio da afirmativa, é possível inferir que o desenvolvimento compreendido em espiral caracteriza-se como um movimento dialético, pois, a cada espaço de interação, é possível vivenciar/experienciar transformações e mudanças, independentemente de ser ou não considerado o sujeito mais ou menos experiente no momento da interação (SCHAPPER, 2010).

Newman e Holzman (2002) discutem, em seu livro Lev Vygotsky: cientista revolucionário, a ZDP como unidade sócio-histórica, atribuindo a ela um caráter revolucionário. Tal abordagem, segundo os autores, pode ser assim considerada, pois as diferentes atividades em instituições sociais nas quais os sujeitos estão imersos não apenas os influenciam, mas, também, contribuem para que estes sejam capazes de transformar as instituições às quais pertencem.

Dito de outro modo, a ZDP é um espaço em que os sujeitos compartilham saberes, vivências e experiências e, juntos, em colaboração, têm a possibilidade de transformar e modificar seu meio. Ao contrário do que alguns pensam, a ZDP não se caracteriza como uma zona calma e estável, mas, sim, de tensões e conflitos, em que há oportunidade de os sujeitos produzirem novos conhecimentos.

Nessa direção, compreende-se que a ZDP revela-se por meio de uma relação complexa, em que estão intrinsecamente imbricados as contradições, as tensões, os conflitos e o "jogo" de forças e poder. Tal relação permite que seja possível a construção de novos significados e não que os já "estabelecidos" assumam posição de petrificação.

O presente estudo comunga da definição que Magalhães (2009), a partir de suas leituras de Vygotsky e de outros pesquisadores que avançaram nos estudos sobre esse autor, 
trouxe para o conceito de ZDP. Segundo a autora (Ibid., p. 61), tal conceito é entendido "como uma zona de ação criativa, uma atividade transformadora "práticocrítica", em que colaboração e criticidade são imprescindíveis à possibilidade de criação de "novas trilhas" (desenvolvimento)". Diante disso, "o foco está na criação de novos significados em que as mediações sociais são "pré-requisito" (instrumento) e "produto" (desenvolvimento)" (MAGALHÃES, 2009, p. 61).

A ZDP pode ser entendida como um espaço propício ao compartilhamento dos sentidos pelos sujeitos, possibilitando um movimento de produção de novos significados. Isso porque é no interior da ZDP que há a possibilidade de se estabelecerem espaços que sejam propícios aos encontros e desencontros, às palavras e contrapalavras, aos confrontos, aos conflitos e também às tensões. Assim, o conceito de ZDP é "entendido como lócus de construção colaborativo-crítico", ou seja, como uma zona em que todos os participantes podem colaborar na discussão (MAGALHÃES, 2009, p. 70).

Com esses argumentos, é possível inferir que, "ao participar das mais diversas atividades na imbricada rede de instituições sociais, não somos apenas influenciados e moldados, mas sobretudo capazes de transformar essas mesmas instituições" (SUZUNDY, 2009, p. 85).

O conceito de ZDP, aliado ao de mediação, auxilia a compreensão dos processos de ressignificação dos sentidos que, consequentemente, desestabilizam os significados que, até determinado momento, apresentam-se estáveis. Isso porque, segundo Aguiar (2006, p. 60):

\footnotetext{
Significado e sentido são momentos do processo de construção do real e dos sujeitos, na medida em que objetividade e subjetividade são também âmbitos de um processo, o de transformação do mundo e constituição dos humanos. Jamais poderão ser considerados e, assim, apreendidos dicotomicamente. Desse modo, será por meio da categoria mediação que construiremos as possibilidades de acessá-los, de apreendê-los na sua singularidade, totalidade e complexidade, em sua unidade dialeticamente contraditória.
}

A categoria "colaboração" é fundamentada, a partir das construções teóricas de Magalhães (2004, 2012), Ibiapina (2008) e Liberali $(2008,2012)$, que a salientam como um elemento para reflexão crítica dos envolvidos. Ou seja, a perspectiva da colaboração é aqui compreendida como um movimento de negociação dos sentidos entre os sujeitos, em que, no referido processo, todos os participantes têm a oportunidade de expor suas vivências, experiências, concordâncias e discordâncias com a palavra do outro com o qual estão em interação. 
Após as discussões travadas acima, a partir das categorias que constituíram parte integrante das categorias de análise da pesquisa aqui tratada, é importante explicitar que a investigação pretendeu analisar o processo argumentativo na formação inicial do pedagogo. Para tal, deu-se destaque aos diálogos tecidos entre aluno-professor-aluno, em uma disciplina que se propõe a pensar sobre as crianças de 0 a 3 anos, buscando identificar o processo argumentativo de tal interação e, por conseguinte, analisar, por meio dos diálogos estabelecidos em sala, se há uma formação crítica do futuro professor para atuação com as crianças pequenas.

\section{Tessituras Metodológicas}

As tessituras metodológicas deste trabalho, esclarece a perspectiva sobre a qual a pesquisa está fundamentada, o contexto da investigação, os instrumentos para sua realização e, por fim, os procedimentos de análise e interpretação dos dados serão apresentados nesta seção.

A pesquisa situa-se numa ordem de cunho qualitativo, com enfoque na perspectiva sócio-histórico-cultural, fundamentada no viés do paradigma crítico de colaboração, Pesquisa Crítica de Colaboração - PCCol (MAGALHÃES, 2004) e no pensamento teórico de Vygotsky e Bakhtin, como explicitado anteriormente. Trabalhar sob a perspectiva sócio-histórico-cultural traduz a busca da transformação da realidade e, assim, o pesquisador não institui uma circunstância para ser investigada, ao contrário, vai ao encontro da situação em seu processo de desenvolvimento e produção (FREITAS, 2002).

Na perspectiva da PCCol, os espaços são de reflexão crítica para a transformação, por meio da colaboração entre os participantes, pois, nesse processo, todos os envolvidos podem expor suas ideias, sendo elas de concordância ou discordância.

Faz-se necessário esclarecer que a investigação buscou, por meio dos diálogos estabelecidos entre aluno-professor-aluno, analisar se as discussões, tecidas em sala possibilitam a formação crítica do futuro professor, pois, segundo Magalhães (2007), nos processos de formação de professores, o compartilhamento de saberes semelhantes e as divergências levam todos os envolvidos a pensarem e a (re)pensarem as práticas pedagógicas.

Portanto, o estudo não visou apenas apontar os fatos e interpretá-los, mas, sobretudo, possibilitar uma transformação dos envolvidos no processo de pesquisa, pois um estudo desenvolvido por meio da perspectiva crítico-colaborativa e que se inscreve na teoria sóciohistórico-cultural permite que o pesquisador e todos os participantes possam repensar suas ações. 
A pesquisa foi permeada de momentos em que os participantes tiveram a oportunidade de construção de novos significados, pois, por meio dos sentidos trazidos por cada participante da comunidade semiótica, esses se confrontavam e, juntos, buscaram um novo contorno, um novo significado. A escolha deste modelo de investigação deve-se à crença de que a formação profissional não pode se limitar aos ambientes formais e escolarizados, pensados e planejados para esse fim. Ao contrário, ela precisa ser "concebida como algo que pode se dar antes, durante e depois do processo formal, como espaços de reflexão sobre o próprio trabalho, em seu próprio contexto de produção" (SCHAPPER, 2010, p. 98).

Assim, os dados gerados nesta investigação foram produzidos a partir de um espaço de ensino-aprendizagem no qual a práxis revolucionária instalada é envolvida com mudanças de totalidades, em que o sujeito transforma a si e ao outro com o qual está em interação, já que o pesquisador intervém no campo pesquisado, no sentido de propiciar espaços de transformações e mudanças.

No contexto das aulas da disciplina de Fundamentos Teórico-Metodológicos em Educação Infantil I, no segundo período do curso de Pedagogia da Faculdade de Educação da Universidade Federal de Juiz de Fora, foi constituído o corpus deste trabalho. Dele fazem parte: filmagens, observações crítico-reflexivas de tal contexto, um questionário e uma sessão reflexiva com os alunos e uma entrevista dialógica com a professora da disciplina. Os procedimentos de produção dos dados desta investigação ocorreram de agosto a dezembro de 2014, contabilizando 15 encontros, pois a disciplina acompanhada tinha quatro horários de cinquenta minutos nas quintas-feiras.

Além das filmagens, que posteriormente foram transcritas e descritas, foi realizada a escrita de notas de campo, pois trazem o registro do que vem à memória, ou seja, o que, diante dos olhos do pesquisador, tomou relevância.

Foi realizada também uma sessão reflexiva com os alunos participantes da pesquisa, em que os enunciados são pensados como contextos nos quais há a possibilidade de momentos em que sentidos podem ser compartilhados para que, juntos, todos possam construir novos significados sobre a prática docente. Importante ressaltar que a sessão reflexiva realizada pautou-se no ciclo de quatro fases proposto por Smyth (1992), quais sejam: descrever, informar, confrontar e reconstruir, etapas que não respeitam uma linearidade, já que se encontram intrinsecamente ligadas nos processos de reflexão.

As discussões estabelecidas, na sessão reflexiva, entre pesquisadora e alunos constituíram-se como um espaço rico para reflexão sobre a teoria e a prática com as crianças de 0 a 3 anos, uma vez que os sujeitos tiveram a oportunidade de compartilhar, por meio de 
uma perspectiva dialógica, os sentidos emergentes relacionados ao trabalho com as crianças pequenas.

Assim, na busca por compreender o processo argumentativo na formação inicial do pedagogo, a análise dos materiais do campo realizou-se por meio da estrutura argumentativa (LIBERALI, 2009), ou seja, pelos tipos de argumento, os operadores argumentativos e os dêiticos. Para tal, foi realizado uso de categorias propostas por Perelman \& Olbrechts-Tyteca (2005) e Koch (2004), visando a discutir a produção de saberes, por meio da argumentação.

É importante discorrer acerca das marcas da interação que constituíram os mecanismos enunciativos ocorridos na sessão reflexiva com os alunos, na entrevista dialógica com a professora da disciplina e também nas observações das aulas acompanhadas, a saber: 0 questionamento, a instrução, a explicação, a retomada de vozes e a colocação e recolocação de problemas. Cumpre notar que é por meio dos movimentos de tais marcas que se torna possível exprimir de que modo foram estabelecidos os diálogos tecidos entre os participantes (LIBERALI; SHIMOURA, 2007).

Além das marcas de interação, estão incluídas no procedimento de análise as marcas linguísticas que, neste trabalho, abrangem os dêiticos espacial, temporal e pessoal e, também, pelos operadores argumentativos $(\mathrm{KOCH}, 2004)$. Por meio de tais elementos, é possível, no momento de análise, assinalar o contexto situacional, bem como a força dos diálogos.

\section{Alguns Apontamentos}

A partir do exposto acima é possível ponderar que alunos, pesquisadora e professora tiveram a oportunidade de vivenciar momentos que contribuíram para a aprendizagem e desenvolvimento dos sujeitos envolvidos no processo de pesquisa. A sessão reflexiva, pautada na perspectiva da PCCol, possibilitou que todos os envolvidos pudessem expor suas ideias, fossem elas de concordância ou discordância, pois, nesse processo, todos os participantes têm voz e vez.

A pesquisa buscou possibilitar, por meio da colaboração crítica entre os participantes, a oportunidade de se constituir um confronto dialético, tendo como foco a discussão da teoria, da práxis e a reflexão crítica de todos os envolvidos.

Portanto, cumpre notar que a investigação revelou, de forma dinâmica, sua produção do conhecimento, uma vez que é constituída por espaços de interações entre os sujeitos e que esses, no movimento de palavras e contrapalavras, têm a oportunidade de, juntos, em um movimento crítico-colaborativo, modificar seu contexto e se revisitarem. 


\title{
INITIAL TEACHER TRAINING AND THE ARGUMENTATIVE PROCESS
}

\begin{abstract}
The present work presents the master's research developed within the Graduate Program in Education of the Federal University of Juiz de Fora - PPGE / UFJF, which focused on the study of the role of argumentation in the initial formation of teachers of the course of Pedagogy of the Federal University of Juiz de Fora. This research is based on the contributions of socio-historical-cultural theory authors: Bakhtin (1995) and Vygotsky (2007) and based on the bias of the Collaborative Critical Research - PCCol (MAGALHÃES, 2004). The discussion of the research data is based on the argumentative categories, based on Perelman and Olbrechts-Tyteca (2005), Liberali (2008, 2009) and Schapper (2010), with a survey of types of arguments, argumentative and deictic operators.
\end{abstract}

Key words: Initial Teacher Training. Child education. Critical Collaboration Research.

Notas explicativas

${ }^{1}$ http://www.anped.org.br/reunioes-cientificas/nacionais

${ }^{2}$ http://www.periodicos.capes.gov.br/

${ }^{3}$ http://www.scielo.org/php/index.php

${ }^{4}$ http://bdtd.ibict.br/

${ }^{5}$ Comunidade semiótica é compreendida, neste texto, como o espaço em comum a algumas pessoas que compartilham dos mesmos signos linguísticos.

\section{Referências}

AGUIAR, Wanda Maria Junqueira. A pesquisa junto a professores: fundamentos teóricos e metodológicos. In: Aguiar, Wanda Maria Junqueira. Sentidos e significados do professor na perspectiva sócio-histórica: relatos de pesquisa. São Paulo: Casa do Psicólogo, 2006.

AMORIM, Marília. O pesquisador e seu Outro: Bakhtin nas Ciências Humanas. São Paulo: Musa Editora, 2004.

BAKHTIN, Mikhail (Volochinov). Marxismo e a filosofia da linguagem. 7a ed. São Paulo: Hucitec, 1995.

BAKHTIN, Mikhail (Volochinov). Estética da criação verbal. Tradução Paulo Bezerra. 6ạ ed. São Paulo: Editora WMF Martins Fontes, 2011.

FREITAS, Maria Teresa de Assunção. A abordagem sócio-histórica como orientadora da pesquisa qualitativa. In: Cadernos de Pesquisa, n.116, p.21-39, julho de 2002.

IBIAPINA, Ivana Maria L. de M. Pesquisa colaborativa: investigação, formação e produção de conhecimentos. Brasília: Líber Livro Editora, 2008. 
JOBIM E SOUZA, Solange. Infância e Linguagem: Bakhtin, Vygotsky e Benjamin. Campinas, SP: Papirus, 1994.

KOCH, Ingedore. A inter-ação pela linguagem. São Paulo: Contexto, 2004.

LIBERALI, Fernanda Coelho. Formação Crítica de Educadores: questões fundamentais. TaubatéSP: Cabral Editora e Livraria Universitária, 2008.

LIBERALI, Fernanda Coelho. A cadeia criativa no processo de tornar-se totalidade. Bakhtiniana: Revista de Estudos do Discurso. São Paulo, vol. 1, n.2, p. 100-124, 2o. sem. 2009.

LIBERALI, Fernanda Coelho. Argumentação em Contexto Escolar. Campinas - São Paulo: Pontes Editores, 2013.

LIBERALI, F. C.; SHIMOURA, A. S. Material didático para a construção da formação crítica: alguns passos para a realização da reunião pedagógica. In: DAMIANOVIC, M. C. (Org.) Material didático: elaboração e avaliação. Taubaté: Cabral Editora e Livraria Universitária, 2007, p. 251267.

LIBERALI, Fernanda; SCHAPPER, Ilka; LEMOS, Mônica. A Pesquisa Crítica de Colaboração (PCCol): diálogos em construção. In: MICARELLO, Hilda; SCHAPPER, Ilka; LOPES, Jader Janer Moreira. Itinerários investigativos: infâncias e linguagens. Juiz de Fora: UFJF, 2012.

MAGALHÃES, Maria Cecília Camargo. A linguagem na formação de professores reflexivos e críticos. In: MAGALHÃES, (org.). A formação do professor como um profissional crítico: linguagem e reflexão. Campinas, SP: Mercado de Letras, 2004.

MAGALHÃES, Maria Cecília Camargo. O método para Vygotsky: a zona proximal de desenvolvimento como zona de colaboração e criticidade criativas. In: SCHETTINI, R. H. [et al]. Vygotsky: uma revisita no início do século XXI. São Paulo: Andross, 2009. p. 53-78.

MAGALHÃES, Maria Cecília Camargo. A pesquisa colaborativa e formação do professor. In: FIDALGO, S; SHIMOURA, A. A pesquisa crítica de colaboração: um percurso na formação docente. São Paulo: Ductor, 2007.

MAGALHÃES, Maria Cecília Camargo; LIBERALI, Fernanda. Grupo de pesquisa linguagem em atividades no contexto escolar (LACE): a linguagem na formação de educadores e alunos colaborativos, críticos e criativos. In: Revista Educação em Foco: diálogos entre as teorias da atividade e sócio-histórico-cultural. Juiz de Fora: Editora UFJF. Edição especial, ago 2012.

NEWMAN, F.; HOLZMAN, L. Lev Vygotsky: cientista revolucionário. Tradução de Marcos Bagno. São Paulo: Edições Loyola, 2002. OBSERVAÇÃO. In: Dicionário do Aurélio Online. Disponível em: http://www.dicionariodoaurelio.com/. Acesso em: 12 de maio de 2014.

PERELMAN, ChaimChaim. \& OLBRECHTS-TYTECA, Lucie. Tratado de Argumentação: A Nova Retórica. (Trad. Maria Ermantina de Almeida Prado Galvão). São Paulo: Martins Fontes, 2005.

SCHAPPER, Ilka. O Fluxo do Significado do Brincar na Cadeia Criativa: argumentação e formação de pesquisadores e educadores. Tese de Doutorado em Linguística Aplicada e estudos da Linguagem, Pontifícia Universidade Católica de São Paulo, 2010. 
SCHAPPER, Ilka; SILVA, Léa Stahlschmidt Pinto. Ação colaborativa na creche: compartilhando sentidos e significados. In: SILVA, Lea Stahlschmidt Pinto; LOPES, Jader Janer Moreira (orgs.). Diálogos de pesquisas sobre crianças e infâncias. Niterói: Editora da UFF, 2010. p. 61-68.

SMYTH, J. Teacher's work and the politics of reflection. American Educational Research Journal, v. 29, no.2, p. 267-300, 1992.

SZUNDY, Paula Tatianne Carréra. Zona de Desenvolvimento Potencial: uma zona de conflitos e revoluções no diálogo pesquisadora-professores. In: SCHETTINI, R. H. [et al]. Vygotsky: uma revisita no início do século XXI. São Paulo: Andross, 2009. p. 53- 78.

VYGOTSKY, Lev Semenovivh. A formação social da mente: o desenvolvimento dos processos psicológicos superiores. Tradução de José Cipolla Neto. 7. ed. São Paulo: Martins Fontes, 2007.

VYGOTSKY, Lev Semenovivh. Pensamento e linguagem. São Paulo: Martins Fontes, 1993. 